BOOKS REVIEWED

\title{
The Book of Jonas
}

By Stephen Dau

Published by Blue Rider Press, 2012, 262 pages

Reviewed by:

Rebecca Bovio (rlb11d@admin.fsu.edu), Career Center Graduate Assistant, The Florida State University

The Book of Jonas describes the journey of a young man, Younis, as he leaves his native country and relocates to the United States. Younis's family dies suddenly when United States military forces annihilate his native town in an unidentified Muslim country. Younis eludes sudden death and escapes to wander the mountains near his village. Wounded and without supplies, Younis almost dies until an American solider finds him and offers aid. Eventually Younis finds his way into the hands of military medical personnel and is given the choice to move to America. During the flight to America, Younis changes his name to Jonas. He begins his new life by living with a foster family, by learning more about American culture, and by beginning his journey through college.

Stephen Dau's writing style includes short, powerful anecdotes rather than one simple narrative. The narrator gives specific glimpses into Jonas's life by recounting specific moments, dreams, memories, and traumas from the past. These anecdotes reveal both gripping insight and elusive detail regarding Jonas's relationship with friends; with his first girlfriend, Shakri; with his psychologist, Paul; and with his environment. The novel follows Jonas as he struggles to find his identity as an international student in a foreign country. Specifically, Jonas struggles to find his identity after facing the death of his family, the destruction of his home, and being uprooted from his village. Eventually, in response to his personal crises, Jonas begins drinking heavily, often waking up in unusual or unfamiliar places. His drinking becomes a concern to his psychologist, his university's administrators, and his girlfriend. The end of the novel finally reveals Jonas's greatest personal crisis and offers slight redemption for Jonas's character.

Unrelated to the journey of a college student, the novel also tracks Christopher, the soldier responsible for finding Jonas and offering aid upon the mountainside. The novel often flashes back to scenes on the mountainside where Jonas recovers from injury, hunger, and dehydration. Christopher keeps Jonas alive with a small pack of supplies. Jonas is the last person to communicate with him before Christopher mysteriously disappears. Because Jonas owes his life to Christopher, the novel also follows the story of Christopher's mother who has never been able to fully cope with her son's disappearance. The U.S. military is unable to give her confirmation or denial regarding her son's disappearance or death. Her grief becomes centripetal in her life, and she forms a national organization for families grieving over missing or deceased soldiers. Her grief, coupled with Jonas's struggles, makes for a truly heart-wrenching novel.

The novel concludes with a dramatic climax when the reader discovers that Jonas has been struggling with the truth of his encounter with Christopher. Jonas, as an adolescent boy, kills Christopher on the mountainside after the U. S. military attack. The literary moment is both beautiful and shocking. As the narrator describes, a silent understanding grows between Jonas and Christopher. Christopher desires to escape the terrible responsibility of unquestioning servitude in the military. Jonas harbors hatred for the soldiers who killed his family and who ravaged his village full of innocent civilians. Simply, Christopher wishes to die, and Jonas wishes to kill. The resulting murder is horrifying yet beautiful in its way, a quick death and a simple solution to the turmoil encompassing 
both Jonas and Christopher.

The novel is clearly and simply written yet also offers profound insight to the growth of a young man dealing with severe trauma. Its greatest strength lies in its exploration of Jonas's identity development and his transition to college. This novel has the potential to incite meaningful conversation regarding identity, new relationships, international students, and mental health services.

Readers will be surprised by the way Dau chooses to describe Jonas's identity development as a young adult. Several key passages speak to the theme of identity, forming identity, or being confused regarding one's identity. Jonas faces significant moments of challenge forcing him to adapt or fail. Towards the beginning of the novel, the narrator describes how Jonas must fill out form after form to create a new "identity" in the United States. Jonas struggles with these forms and struggles with how he identifies himself. A new college student might consciously or subconsciously recognize similar feelings regarding their transition to college, perhaps questioning how their identity is being created and shaped. Jonas's identity exploration is perhaps the most helpful element to incite dialogue among new students or those working with new students. Faculty, staff, or orientation leaders might lead dialogue asking how new students identify themselves, racially, ethnically, socioeconomically, or sexually. The importance of understanding one's identity is evident in this novel and would be easily understood by a student reader.

Dau also spends adequate time developing Jonas's new relationships with friends and with his first girlfriend, another possible topic of conversation. The narrator describes Jonas's group of friends and how they manage to create a cohesive social structure. The narrator describes how Jonas meets his girlfriend and how their relationship progresses and eventually ends. I find these descriptions useful for a new college student because they are realistic. Rather than idealizing the collegiate experience, the novel demonstrates the conflict that may arise in relationships, the typical nights hanging out, and the dangers of living independently and irresponsibly. Dau portrays Jonas and his friends in a very realistic manner in the way they act, speak, and interact, a useful element of the novel.

Interestingly, this book also offers key passages that might incite meaningful discussion regarding international students. Crisis aside, Jonas is an international student who learns to engage with the American educational system and its students. In the book, Jonas is most easily accepted by and comfortable around other international students. Although they have their internationality as a commonality, Jonas's group of friends is extremely diverse with varying personalities, nationalities, religions, and opinions. Exploring his friendships with these individuals might be an issue for discussion as well. Many institutions of higher education seek to educate their students about diversity, living in a diverse world, and contributing to a global community. This novel may inspire students to think about how they might commence creating their social circles and how a diverse group of peers may be beneficial.

Lastly, this novel may provide dialogue points regarding the necessity or helpfulness of mental health services for college students, especially students with past trauma or identity crises. As a student having faced severe trauma and the loss of his family, Jonas struggles with his past colliding with his present and future. After a pseudo-violent incident, Jonas is assigned mandatory counseling. As the novel progresses, Jonas begins to perform poorly in school, takes to heavy drinking, and possesses little ambition for the future. Although Jonas is not often willing to talk, his visits with his psychologist, Paul, result in Jonas finally facing his greatest trauma. Although Jonas's experiences are extreme, an average student might recognize the occasional necessity of seeking mental health services, and the novel may educate students regarding the warning signs of a student struggling with unspoken crisis. 
Although several of the aforementioned themes seem useful for incoming college students, I do have several major concerns regarding this novel. First, Jonas's character faces the extreme circumstance in which his family is killed and his home and village are destroyed; he faces death, and he commits murder. While these circumstances may represent challenge or crisis as means for development, these types of crises are far beyond the circumstances an average student would ever face, nor will they regularly interact with other students having faced such extreme life circumstances. Because of this, I find that the novel becomes somewhat unrelatable for the general student reader. Although students may relate to identity development and identity crisis, I do not believe students would retain a lasting connection to Jonas's character.

Second, I am concerned that the content of Dau's novel often portrays student life in a negative manner. Jonas assumes the habit of drinking heavily with some of his friends. At one point, he is arrested and put on academic probation from his university. It is also implied that Jonas has a sexual relationship with his girlfriend. In my opinion, students should not read these scenarios and believe that they should be or are the norm for college life. Some institutions, particularly religiously affiliated universities, may not feel inclined to offer this type of reading material to their incoming students due to the descriptions of alcohol consumption and sexual activity.

Third, in many ways, Dau's novel evokes sympathy and sadness, which may have a negative affect on student readers. Jonas continues to struggle throughout the novel to find his place and meaning in life, and in many ways, he fails to fully transition as a college student and as an individual in America. In perhaps one of the most powerful moments of the book, Jonas has lost almost everything, and it is seems possible that he may commit suicide. In this scene of the novel, the narrator describes Jonas:

He struggles with categories. He can neither place himself into a context, nor can he be placed. The usual labels fail. He is a victim. His is a perpetrator. He is a terrorist. He is a refugee. He feels himself placed neatly into boxes. He fights against labels. He is omni scient. He is a criminal. (p. 232)

Although Jonas eventually finds redemption, the reader is left with a sense of sadness over a young man having faced such devastating losses. Toward the end of the novel, Jonas tells his therapist that he feels he is running out of time. Dau's novel is not the most uplifting or encouraging story. This is not the type of message to send to a new student transitioning into college life. The transition to college should be a time to celebrate, and the serious and extreme subject matter of this novel may provide an improper message or be overwhelming for the average incoming student.

Lastly, as mentioned, midway through the novel, the story begins to focus on Rose, Christopher's mother and her personal search for peace after her son's disappearance. I do not find any obvious or immediate connection between her story and the life of college students. While she faces her own demons and identity struggle, they have little to do with the transition to college. A large portion of the second half of the novel is dedicated to her struggle, and I feel it detracts from the message a student might have received from reading and relating to Jonas's story. In my opinion, this is my greatest concern for this book, that by including so much of Rose's story, the connection to college becomes slightly blurred or lost.

I am not confident that this book is the most appropriate or useful for New Student Programs or Orientation offices, and ultimately, I do not suggest this book for a general student population. Because of its very specific content, I am not sure students would find a lasting connection to Jonas's character. Although the book is well written and easy to read, Jonas's character simply faces too many extreme circumstances to be fully relatable. A student would have to read metaphorically and deeply into the story to grasp how this novel might be relevant.

However, Dau's novel is not without merits. It may be suitable for special interest groups or colleges and universities with a high veteran population. This book may be useful in smaller settings 
in which a group of students has time for deep and meaningful discussion. Discussion might include the themes aforementioned, how the novel relates to university life, and the lessons learned from the novel. Veterans may have experienced extreme circumstances during active duty, or they may relate to the military aspects of this novel including loss, sacrifice, and endurance. Thus, I recommend this novel in two instances. One, I suggest this novel for colleges or universities with a high veteran population that may relate to Jonas and the content of the novel. Two, I suggest this novel specifically for special or freshman interest groups in which students are given a summary of the book and would be willing to dive into the exploration of the novel's themes.

Should a university choose to use this book for the general student population, a summary should be available, and I suggest the reading be given an intentional theme such as understanding diversity or differences, the importance of mental health, or the importance of engaging with international students. Because this book may better serve a targeted audience, New Student Programs or Orientation offices might partner with Counseling Centers, International Student Centers, or Veteran support groups to use this book in a collaborative programming effort. These offices correspond with the major themes I discussed earlier in this review.

As mentioned, The Book of Jonas possesses the potential to engage students, faculty, and staff in conversations regarding a number of topics including, but not limited to, identity development, relationships, international students, and the importance of mental health services. I very much enjoyed reading Dau's novel; I was both engaged and entertained through its entirety. Although the novel merits some attention as a first-year or common reading option, my recommendation is to forego this choice or to use this novel within a small group context. 